\title{
Combined Infection of Human Herpes Viruses: A Risk Factor for Subsequent Colectomy in Ulcerative Colitis
}

Shuhei Hosomi, Kenji Watanabe, Yu Nishida, Hirokazu Yamagami, Tomomi Yukawa, Koji Otani, Yasuaki Nagami, Fumio Tanaka, Koichi Taira, Noriko Kamata, Tetsuya Tanigawa, Masatsugu Shiba, Toshio Watanabe, Hisashi Nagahara, Kiyoshi Maeda, Yasuhiro Fujiwara

\begin{tabular}{|c|l|}
\hline Citation & Inflammatory Bowel Diseases, $24(6) ; 1307-1315$ \\
\hline Issue Date & $2018-06$ \\
\hline Type & Journal Article \\
\hline Textversion & author \\
\hline Rights & $\begin{array}{l}\text { This is a pre-copyedited, author-produced version of an article accepted for publication } \\
\text { in Journal of Crohn's and Colitis following peer review. The version of record : Shuhei } \\
\text { Hosomi et al.; Combined Infection of Human Herpes Viruses: A Risk Factor for } \\
\text { Subsequent Colectomy in Ulcerative Colitis, Inflammatory Bowel Diseases, Volume } \\
24, \text { Issue 6, pages 1307-1315, is available online at: https://doi.org/10.1093/ibd/izy005 }\end{array}$ \\
\hline DOI & $10.1093 /$ ibd/izy005 \\
\hline
\end{tabular}

Self-Archiving by Author(s) Placed on: Osaka City University

HOSOMI, S., et al. (2018). Combined Infection of Human Herpes Viruses: A Risk Factor for Subsequent Colectomy in Ulcerative Colitis. Inflammatory Bowel Diseases. 24, 1307-1315. https://doi.org/10.1093/ibd/izy005. 


\section{Title}

Combined infection of human herpes viruses: a risk factor for subsequent colectomy in ulcerative colitis

\section{Short title}

\section{HHV in IBD}

Shuhei Hosomi, MD, PhD, ${ }^{*}$ Kenji Watanabe, $\mathrm{MD}, \mathrm{PhD},{ }^{\dagger} \mathrm{Yu}$ Nishida, MD, PhD, Hirokazu Yamagami, MD, PhD, ${ }^{*}$ Tomomi Yukawa MD, PhD, ${ }^{*}$ Koji Otani, MD, PhD, Yasuaki Nagami, MD, PhD, ${ }^{*}$ Fumio Tanaka, MD, PhD, Koichi Taira, MD, PhD, Noriko Kamata, MD, PhD, ${ }^{*}$ Tetsuya Tanigawa, MD, PhD, ${ }^{*}$ Masatsugu Shiba, MD, PhD, ${ }^{*}$ Toshio Watanabe, MD, PhD, ${ }^{*}$ Hisashi Nagahara, MD, PhD ${ }^{\ddagger}$ Kiyoshi Maeda, MD, $\mathrm{PhD},{ }^{*}$ Yasuhiro Fujiwara, $\mathrm{MD}, \mathrm{PhD},{ }^{*}$

* Department of Gastroenterology, Osaka City University Graduate School of Medicine, Osaka, Japan †Department of inflammatory Bowel Disease, Hyogo College of Medicine, Hyogo, 
Japan

\$Department of Surgical Oncology, Osaka City University Graduate School of

Medicine, Osaka, Japan

\section{Corresponding author:}

Shuhei Hosomi,

Department of Gastroenterology, Osaka City University Graduate School of Medicine,

1-4-3, Asahi-machi, Abeno-ku, Osaka 545-8585, Japan.

Tel: 81-6-6645-3811

Fax: 81-6-6645-3813

E-mail: m1265271@,med.osaka-cu.ac.jp

\section{Conflict of Interest and Source of Funding}

The authors declare no conflict of interest and received no specific funding for this work.

\section{Abbreviations}


AZA, azathioprine; CD, Crohn's disease; CI, confidence interval; CMV, cytomegalovirus; CyA, cyclosporine A; EBV, Epstein-Barr virus; HHV, human herpes virus; HR, hazard ratio; HSV, herpes simplex virus; IBD, inflammatory bowel disease; IFX, infliximab; MES, Mayo endoscopic subscore; PCR, polymerase chain reaction; TAC, tacrolimus; TNF, tumor necrosis factor; UC, ulcerative colitis; VZV, Varicella-Zoster virus; 5-ASA, 5-aminosalicylic acid; 6-MP, 6-mercaptopurine 


\begin{abstract}
Background: Little is known about the prevalence and pathogenicity of human herpes viruses except for cytomegalovirus (CMV) in patients with inflammatory bowel disease (IBD). The aim of this study was to determine the prevalence of human herpes viruses on colonic mucosa in patients with IBD and assess the long-term outcomes in these patients.
\end{abstract}

Methods: We examined the colonic mucosal specimens from 66 patients with ulcerative colitis (UC), 54 patients with Crohn's disease (CD), and 29 healthy patients to identify the six most common types of human herpes virus, using multiplex polymerase chain reaction (PCR) technique.

Results: Herpes simplex virus (HSV)-1/2 and varicella-zoster virus (VZV) were not detected in any of the groups. There was a higher prevalence of Epstein-Barr virus (EBV) $(21.2 \%)$ and CMV (15.1\%) in patients with UC than in patients with CD (EBV 9.3\%, CMV 0\%) and the healthy control group (EBV 0\%, CMV 3.4\%). The prevalence of human herpes virus (HHV)-6A/B and HHV-7 was not statistically different among the groups. Five UC patients with inflammation had coexisting CMV and EBV or HHV-6. The combined infection of CMV with EBV or HHV-6 was a significant and 
independent prognostic factor for subsequent colectomy in patients with UC.

Conclusions: The increased prevalence of CMV coexisted with EBV/HHV-6 infection was associated with the clinical course in patients with UC.

\section{Keywords}

human herpes virus, Epstein-Barr virus, cytomegalovirus, human herpes virus-6, ulcerative colitis, Crohn's disease 


\section{Introduction}

Crohn's disease (CD) and ulcerative colitis (UC), which are chronic and relapsing forms of inflammatory bowel disease (IBD), have been suggested to be complex multifactorial diseases, with genetic factors, mucosal barrier function, immune response, and environmental factors, including infectious agents playing a role ${ }^{1,2}$. Although no infectious agent has been identified as the cause of IBD, many pathogens have been suggested to be a trigger and/or refractory factor in patients with IBD ${ }^{3}$. Recently, loss of immune tolerance to commensal enteric bacteria is hypothesized to be one of the pathogenic mechanisms of IBD. Several IBD susceptibility genes associated with innate immunity and autophagy (e.g., NOD2/CARD15, ATG16L1, IRGM) contribute to this phenomenon ${ }^{4,5}$. The reactivation of herpes simplex virus type (HSV)-1, varicella zoster virus (VZV), Epstein-Barr virus (EBV), cytomegalovirus (CMV), and human herpes virus type (HHV)-6, which belong to the herpesviridae family of viruses with a double-stranded DNA, cause several symptoms in severe immunocompromised hosts, such as individuals who undergo hematopoietic stem cell transplantation ${ }^{6,7}$. CMV reactivation was frequently identified in the colonic mucosa of IBD patients, and this was associated with a significant clinical morbidity, such as a toxic megacolon, 
requirement of colectomy, and high mortality rate ${ }^{8,9}$. Several studies have described the significant presence of EBV in colonic specimens of IBD patients ${ }^{10,11,12}$. In contrast, there are few reports describing other human herpes viruses in patients with IBD. A recent study showed that $26.8 \%$ and $10.1 \%$ of UC patients are positive for EBV and HHV-6 in stool samples, respectively ${ }^{13}$. This study also showed that $22.4 \%$ and $1.7 \%$ of active UC patients had combined prevalence of CMV with EBV and CMV with HHV-6, respectively, implicating that combined infection may be related to the pathogenesis of UC. More resent research evaluated human herpes viruses by PCR in colonic mucosa of immunocompetent patients, IBD patients, and human immunodeficiency virus-infected patients, which revealed that the positivity rates of EBV and CMV, but not of the other human herpes viruses, increased in the order of the immunocompetent patients, the IBD patients, and the human immunodeficiency virus-infected patients (EBV, 23.1\%, 53.7\%, 72.7\%; CMV, 7.7\%, 24.4\%, 54.5\%, respectively) ${ }^{14}$. However, there are no studies demonstrating the clinical meaning of other human herpes viruses or combined infection of human herpes viruses with CMV in IBD.

The aim of this study was to determine the prevalence and the risk factors of human 
herpes virus family on colonic mucosa in patients with IBD. In addition, we investigated the long-term outcomes in these patients.

\section{Materials and Methods}

\section{Patients and Samples}

The diagnosis of IBD is based on clinical, endoscopic, and histopathological findings. Mucosal specimens were collected between January 2007 and September 2010 with biopsies from the rectosigmoid colon during colonoscopy or surgical resected specimens of the rectosigmoid colon. For comparison, control biopsy specimens were taken from the normal rectosigmoid mucosa of patients who underwent colonoscopy for various reasons (e.g., cancer screening). Endoscopic activity was determined on rectosigmoid colon for $\mathrm{CD}$, using an endoscopic score of $0-2(0$, normal; 1 , light erythema or granularity; 2, granularity, friability, and bleeding, with or without ulcerations) according to Froslie's criteria ${ }^{15}$, with a score of 0 or 1 regarded as noninflamed. For UC, endoscopic activity was assessed by Mayo endoscopic subscore (MES) ${ }^{16}$, with a score of 0 regarded as noninflamed. Montreal classification ${ }^{17}$ was used to classify the disease extent, which included proctitis (E1), left-sided colitis (E2), 
or Pancolitis (E3) for UC; disease location included ileal (L1), colonic (L2), or ileo-colonic (L3); and behavior included inflammatory (B1), stricturing (B2), or penetrating disease (B3) for CD.

\section{Multiplex polymerase chain reaction}

DNA was extracted from sigmoid colon samples, using QIAamp DNA Mini Kit

(Qiagen, Tokyo, Japan) according to the manufacturer's instructions. To detect and identify the 6 most common types of human herpes virus (HSV-1/2, VZV, EBV, CMV, HHV-6A/B, and HHV-7), we used multiplex polymerase chain reaction (PCR) technique and specific primers as described previously ${ }^{18}$ (Table 2). Each primer pair was designed with different amplicon size to identify each product with agarose gel electrophoresis. PCR was performed in $50 \mu \mathrm{L}$ volumes, using AmpliTaq Gold PCR Master Mix (Applied Biosystems, Foster City, CA, USA), $0.2 \mu \mathrm{M}$ of each primer, and 5 $\mu \mathrm{L}$ of DNA extract. After initial denaturing DNA at $95^{\circ} \mathrm{C}$ for 10 minutes, the amplification reaction was carried out in a Veriti 96-well thermal cycler (Applied Biosystems) with preliminary denaturation for 10 minutes at $95^{\circ} \mathrm{C}$, followed by touchdown protocol for the first 10 cycles of denaturation at $95^{\circ} \mathrm{C}$ for 30 seconds, 
annealing at $70^{\circ} \mathrm{C}$ to $61^{\circ} \mathrm{C}$ for 30 seconds with decrease of $1{ }^{\circ} \mathrm{C}$ for each cycle, and extension at $72^{\circ} \mathrm{C}$ for 1 minute. Afterward, additional 35 cycles of $95^{\circ} \mathrm{C}$ for 30 seconds, $60^{\circ} \mathrm{C}$ for 30 seconds, and $72^{\circ} \mathrm{C}$ for 30 seconds were carried out. The amplified products were visualized by ethidium bromide staining and UV transillumination, following electrophoretic separation on 3\% agarose gels. A combined infection group was defined as patients positive for DNA of two or more human herpes viruses, and single-infection group was defined as patients positive for DNA of only one human herpes virus.

\section{Statistical analysis}

Continuous variables are represented as median and interquartile range (IQR).

Fisher's exact test was used to compare the differences in the prevalence of each viral infection among groups. Factors associated with viral infection were analyzed, using a univariate logistic regression model. Subsequently, factors with $P<0.2$ in univariate analysis were included in the multivariate analysis. The data were presented as odds ratio (OR) with 95\% confidence intervals (CI). Risk factors for colectomy were analyzed, using univariate and multivariate Cox proportional hazard model with adjustment for partial Mayo score, Mayo endoscopic subscore (MES), serum albumin 
level, serum C-reactive protein level, and anti-viral therapy.. The data were presented as hazard ratios (HR) with 95\% CI. Differences were considered significant when $P$ values were less than 0.05. All statistical analyses were performed with EZR (Saitama Medical Center, Jichi Medical University), a graphical user interface for R (The R Foundation for Statistical Computing, version 2.13.0). More precisely, it is a modified version of $\mathrm{R}$ commander (version 1.6-3) that includes statistical functions frequently used in biostatistics.

\section{Ethical Considerations}

Ethics Committee of Osaka City University approved this study to obtain the mucosal specimens (protocol number 2286). Informed consent was obtained from all patients and healthy controls. The protocol for obtaining and analyzing long-term outcomes (protocol number 3712) was approved by the ethics committee of Osaka City University Hospital. The ethics committee granted exemption from written informed consent for the long-term analysis because the analysis used anonymized clinical data that were retrospectively obtained after each patient agreed to treatment by written consent. Nevertheless, all patients were notified of the content and information on this 
study, and they were given the opportunity to refuse participation. None of the patients refused participation. This procedure followed the Ethical Guidelines for Medical and Health Research Involving Human Subjects established by the Ministry of Education, Culture, Sports, Science and Technology and the Ministry of Health, Labour and Welfare in Japan.

\section{Results}

Study population and prevalence of human herpes viruses in colonic mucosa by multiplex polymerase chain reaction

Twenty-nine healthy controls, 66 patients with UC, and 54 patients with CD were included in this study. The median age of the controls, the patients with UC, and the patients with CD was 64.9 years (IQR, 58-73 years), 48.3 years (IQR, 34.5-60.8 years), and 36.9 years (IQR, 28.3-42 years), respectively. The percentage of mucosal inflammation in patients UC and CD patients was 54.5\% (36 inflamed and 30 noninflamed specimens) and 25.9\% (14 inflamed and 40 noninflamed specimens), respectively. Mesalamine, corticosteroids, immunomodulators (azathioprine or 6-mercaptopurine), calcineurin inhibitors (cyclosporine or tacrolimus), and infliximab 
were used in $81.8 \%, 30.3 \%, 12.1 \%, 6.8 \%$ and $1.5 \%$ of UC patients and $75.9 \%, 3.7 \%$, $35.2 \%, 0.0 \%$ and $37.0 \%$ of CD patients, respectively (Table 1 ).

HSV-1/2 and VZV were not detected in the colonic mucosa of any of the patients (Table 3). EBV was found in 14 of the $66(21.2 \%)$ patients with UC and five of the 54 (9.3\%) patients with $\mathrm{CD}$; however, none of the subjects in the control group was positive for EBV. The difference in the prevalence of EBV infection among patients with UC, patients with $\mathrm{CD}$, and the healthy controls was significant $(P<0.001$ by Fisher's exact test). CMV was found in one of the 29 (3.4\%) healthy controls, 10 of the $66(15.1 \%)$ UC patients, and none of the $54 \mathrm{CD}$ patients. The difference in the prevalence of CMV infection among patients with $\mathrm{UC}$, patients with $\mathrm{CD}$, and the healthy controls was significant $(P=0.003)$. HHV-6A/B was detected in two of the 29 $(6.9 \%)$ subjects in the control group, six of the 66 patients with $(9.1 \%) \mathrm{UC}$, and five of the $54(9.3 \%)$ patients with CD. There was no difference in the prevalence of HHV -6 infection among patients with UC, patients with $\mathrm{CD}$, and the healthy controls $(P=$ 1.000). None of the 29 subjects in the control group had HHV-7, while it was found in one of the $66(1.5 \%)$ patients with UC, and two of the $54(3.7 \%)$ patients with CD. There was no difference in the prevalence of HHV-7 infection among patients with UC, 
$\mathrm{CD}$, and the healthy controls $(P=0.594)$. Analysis of relation between the prevalence of human herpes viruses and endoscopic severity according to Mayo endoscopic subscore (MES) showed that severe colitis (MES 2 or 3) of UC had higher prevalence of CMV infection, MES 0, 3.3\%; MES 1, 0\%; MES 2, 29.4\%; MES 3, 28.6\% $(P=0.019)$, but not EBV and HHV-6A/B (Table 4).

Five out of the total 149 patients had the combined infection with EBV and CMV, and all five were in patients with UC and inflammation. One out of the total 149 patients had the combined infection with EBV and HHV-6; one out of 149 patients had the combined infection with CMV and HHV-6. All the patients with combined infections were those with UC (Fig. 1). None of the patients were infected with HHV-7 and other viruses.

\section{Associations between baseline characteristics and the human herpes virus infection}

\section{in inflammatory bowel disease}

Recent meta-analysis showed that use of corticosteroids and thiopurines are associated with CMV reactivation in IBD ${ }^{19}$. To identify factors associated with EBV, CMV, and HHV-6 infection in IBD, the factors, including concomitant medications 
were analyzed using logistic regression analysis. Univariate logistic regression analysis revealed that existence of mucosal inflammation and use of corticosteroids, cyclosporine A (CyA), or tacrolimus (TAC) were significant risk factors for EBV infection (Table 5). Multivariate logistic regression analysis also identified the existence of mucosal inflammation as a significant and independent risk factor for EBV infection (OR: 7.56, $P=0.002$ ) (Table 6). Existence of mucosal inflammation and use of corticosteroids were identified as significant risk factors for $\mathrm{CMV}$ infection by univariate logistic regression analysis (Table 5). Multivariate logistic regression analysis revealed that older age (OR: $1.06, P=0.054)$ and use of corticosteroids (OR: 5.24, $P=$ 0.064) tended to increase the risk of CMV infection (Table 6). We found no significant risk factors associated with the HHV-6 infection in our univariate and multivariate analyses (Table 5 and 6).

\section{Association between combined infection of human herpes viruses and long-term}

\section{outcome of ulcerative colitis}

A recent study has shown that about one-fourth of active UC patients had combined prevalence of EBV or HHV-6 with CMV ${ }^{13}$. Our study also showed that $10.6 \%$ of 
patients with UC had combined infection, but none of the patients with $\mathrm{CD}$ had a combined infection. The question here was whether the combined infection in colonic mucosa of UC patients was the primary cause of mucosal inflammation or a secondary event to severe disease. To address the question, we next evaluated the clinical course of patients with UC. The median duration of follow-up was 78.2 months (IQR, 46.3-81.5 months). Univariate COX proportional hazard analysis revealed a significant relationship between colectomy-free survival and combined infection $(P=0.019)$ (Table 7). Multivariate analysis adjusted for partial Mayo score, Mayo endoscopic subscore (MES), serum albumin level, serum C-reactive protein level, and anti-viral therapy showed that combined infection was significant and independent prognostic factors for subsequent colectomy (adjusted $\mathrm{HR}=72.3,95 \% \mathrm{CI}$ : $1.85-2.82 \mathrm{E}+03, P=0.022)$ (Table 7), although single infection was not significant and was not an independent prognostic factor $(P=0.824)$. The benefit of antiviral therapy on the long-term outcome of UC patients with CMV has not been well established ${ }^{20,21}$. Six UC patients with CMV were followed to analyze long-term outcome in this study. Four CMV positive patients had mucosal inflammation, and two of them were treated by anti-viral therapy by ganciclovir. Therefore, we assessed anti-viral therapy as a risk factor for subsequent 
colectomy, which showed no efficacy of the anti-viral therapy in this study (multivariate Cox proportional analysis, $P=0.595$ ) (Table 7).

\section{Discussion}

In this study, we demonstrated higher prevalence of CMV and EBV in colonic mucosa of patients with UC than in healthy controls and patients with CD. We also showed that a combined infection of EBV or HHV-6 with CMV is independently and significantly associated with an increased risk of colectomy in UC.

Eight types of herpes viruses are known to be pathogenic (HSV-1, HSV-2, VZV, EBV, CMV, HHV-6, HHV-7, and HHV-8) ${ }^{6}$. In the present study, we used the multiplex PCR technique for the diagnosis of these human herpes infections in the colonic mucosa of 29 healthy patients and 120 patients with IBD (UC or CD). There are several methods for detecting these viral infections, such as histology (including immunohistochemistry), serologic assays, culture, PCR for viral DNA, and viral antigenemia. PCR is reported to be the most sensitive way to detect these viruses ${ }^{22}$. The multiplex PCR technique we used is of high specificity and sensitivity; the detection limit for each virus was approximately 20 DNA copies per reaction. Moreover, this 
method does not need expensive equipment and complicated processes ${ }^{23}$. Therefore, multiplex PCR is an economical, quick, and useful screening method for such viral infection.

None of the subjects, both the healthy controls and those with IBD, had HSV-1/2 or VZV in their colonic mucosa. The most common site of the HSV involvement in immunocompromised host is the esophagus, and the involvement of the colon is very rare ${ }^{24}$. Only a few cases of HSV colitis in IBD have been described in the English-language literature ${ }^{25-27}$. Patients with IBD who use immunosuppressive medications are at high risk for VZV reactivation ${ }^{28}$; however, the involvement of the colon is also very rare ${ }^{29}$.

HHV-7 infection was found infrequently in our study, and the prevalence of the HHV-7 infection did not differ between the control group and the group with IBD patients. A recent study evaluating human herpes viruses showed that $30.8 \%$ of immunocompetent patients and $39.0 \%$ of IBD patients were positive for HHV-7, although the positivity rates did not differ between each group ${ }^{14}$. The positivity rates of human herpes viruses (EBV, CMV, HHV-6, and HHV-7) in the study were higher than ours. This discrepancy might be due to different assay (standard vs multiplex PCR, 
different primer pair) or different background of patients. Information on the pathogenic role of HHV-7 reactivation in immunocompromised host is still very limited ${ }^{30}$.

Nineteen $(15.8 \%)$ patients with IBD were positive for EBV in the present study, which is the highest prevalence reported. The prevalence of EBV in IBD patients was significantly higher than that in the controls. The association between EBV infection and the development of neoplasia has been known, especially in immunocompromised host ${ }^{31}$. Several studies have described the significant presence of EBV in colonic specimens of IBD patients compared to the control group 10,11,12,32. Recently, Sankaran-Walters et al. reported that proliferating B-lymphocytes in inflamed colonic mucosa of IBD patients expressed high EBV genes ${ }^{33}$. Weinberg et al. reported a patient with IBD whose condition was exacerbated by EBV infection ${ }^{34}$. EBV-encoded dUTPase could enhance production of proinflammatory cytokines such as IL-6, and the tumor necrosis factor (TNF)- $\alpha$ by monocytes/macrophages ${ }^{35}$. Our logistic regression analysis also showed that colonic mucosal inflammation and use of corticosteroids, CyA, or TAC were associated independently with EBV infection, indicating that EBV infection or reactivation might be associated with intestinal inflammation of IBD under immunocompromised conditions similar to CMV reactivation in UC. However, it is 
unclear whether the EBV detected in colonic mucosa was the primary cause of the mucosal inflammation or a secondary event to severe disease. Further basic and clinical studies will be needed.

Ten $(8.3 \%)$ patients with IBD were positive for CMV, although only one was positive in the control group. The prevalence of CMV in patients with UC (13.9\%) was higher than that in the control group (3.4\%) and patients with $\mathrm{CD}(0 \%)$. Nine out of 10 CMV-positive patients with IBD had UC with inflamed colonic mucosa. Indeed, some investigators also reported that CMV infection was seen infrequently $(0-3.6 \%)$ in colonic mucosa of patients with $\mathrm{CD}^{32,36,37}$. As for UC, CMV infection has been found more frequently in active patients $(20-60 \%)^{38-42}$, although inactive patients do not exhibit any evidence of CMV infection ${ }^{41,43}$. The pathogenesis of $\mathrm{CD} T$ helper cell (Th)-1-shifted activation of cellular immunity, including IFN- $\gamma$ production plays an important role in the pathogenesis of $\mathrm{CD}$, and this IFN- $\gamma$ could suppress $\mathrm{CMV}{ }^{44}$.In contrast, TNF- $\alpha$ was reported to be associated with CMV activation in patients with UC. 45. This is considered as one of the reasons why CMV reactivation is more frequently observed in patients with UC than those with $\mathrm{CD}^{46}$. The present study showed that older age and use of corticosteroids had the tendency to increase the risk of CMV 
infection, which is consistent with findings from several previous studies ${ }^{41,46-48}$. Some basic research has shown that steroids and TNF could enhance CMV replication ${ }^{49-51}$; therefore, persistent and uncontrolled inflammation might cause the reactivation of CMV, particularly in patients who are on corticosteroids treatment.

Only a few cases of HHV-6 associated colitis have been reported ${ }^{52,53}$, although HHV-6 reactivation can cause encephalitis in the immunocompromised patients. In the present study, HHV-6 was detected in $9.2 \%$ (11/120 cases) of the patients with IBD; however, there was no difference in the prevalence among patients with UC, patients with $\mathrm{CD}$, and the healthy controls. Moreover, no significant risk factor associated with HHV-6 infection was found in our logistic regression analysis. These indicate that HHV-6 infection in the colon is not related to mucosal inflammation in IBD.

The pattern of coexistence of CMV and EBV or HHV-6 in colonic mucosa is another intriguing finding of the present study. Five of $11(45 \%)$ and one of $11(9 \%)$ UC patients with CMV are coexistening with EBV and HHV-6, respectively. Moreover, all six patients with combined infection were those with UC. HHV-6 could be a co-factor for the development of CMV infection in patients undergoing transplantation ${ }^{54,55}$. Likewise, Aalto et al. demonstrated EBV reactivation in a large proportion of patients 
with CMV primary infection ${ }^{56}$. These findings suggest that such interactions between CMV and other human herpes viruses might promote mucosal inflammation in IBD, particularly in UC. We, therefore, evaluated long-term outcome of UC patients with combined infection of CMV with EBV or HHV-6 to understand the pathogenic role of these infections in the clinical course. Multivariate analysis showed that combined infection, but not single infection, was the significant and independent prognostic factors for subsequent colectomy, implicating that EBV or HHV-6 infection could synergistically lead to exacerbation of intestinal inflammation or promote CMV reactivation in $\mathrm{UC}$, resulting in higher rate of colectomy.

Our study has some limitations. First, this study is a retrospective study with a relatively small cohort. The small sample number, especially on long-term analysis for patients with UC, resulted in wide CI. Second, multiplex PCR assay used in this study was not quantitative PCR. Third, both biopsy samples under endoscopy and surgical resected specimens were analyzed, which could influence the result of PCR. Finally, our study did not include immunohistochemistry, antigenemia assay, and serological tests. Further prospective studies are needed to clarify these problems and validate the present findings. 
In summary, we demonstrated that the prevalence of CMV and EBV in the patients with UC was higher than that in healthy controls and patients with CD using multiplex PCR method. Mucosal inflammation was associated with the risk of EBV infection. The coexistence of $\mathrm{CMV}$ and $\mathrm{EBV} / \mathrm{HHV}-6$ infections was associated with the subsequent colectomy in patients with UC, suggesting a synergistic role of these viruses in contributing to trigger or exacerbate the mucosal inflammation in UC.

\section{Acknowledgement}

All authors agree with this submission. SH and HY made substantial contributions to the concept of this study. SH, HY, TY, NK, HN, and KM made substantial contributions to data and samples acquisition. SH and TY made substantial contributions to data analysis. SH and HY made substantial contributions to manuscript writing. KO, YN, FT, KT, TT, MS, TW, and YF made substantial contributions to reviewing and editing this manuscript.

\section{References}

1. Abraham C, Cho JH. Inflammatory bowel disease. The New England journal of 
medicine 2009; 361(21): 2066-78.

2. Kaser A, Zeissig S, Blumberg RS. Inflammatory bowel disease. Annual review of immunology 2010; 28: 573-621.

3. Hansen R, Thomson JM, El-Omar EM, Hold GL. The role of infection in the aetiology of inflammatory bowel disease. Journal of gastroenterology 2010; 45(3): 266-76.

4. Cho JH. The genetics and immunopathogenesis of inflammatory bowel disease. Nature reviews Immunology 2008; 8(6): 458-66.

5. Fritz T, Niederreiter L, Adolph T, Blumberg RS, Kaser A. Crohn's disease: NOD2, autophagy and ER stress converge. Gut 2011; 60(11): 1580-8.

6. Ljungman P. Herpes virus infections in immunocompromised patients: problems and therapeutic interventions. Annals of medicine 1993; 25(4): 329-33.

7. Razonable RR, Paya CV. Herpesvirus infections in transplant recipients: current challenges in the clinical management of cytomegalovirus and Epstein-Barr virus infections. Herpes : the journal of the IHMF 2003; 10(3): 60-5.

8. Orloff JJ, Saito R, Lasky S, Dave H. Toxic megacolon in cytomegalovirus colitis. The American journal of gastroenterology 1989; 84(7): 794-7. 
9. Papadakis KA, Tung JK, Binder SW, et al. Outcome of cytomegalovirus infections in patients with inflammatory bowel disease. The American journal of gastroenterology 2001; 96(7): 2137-42.

10. Wakefield AJ, Fox JD, Sawyerr AM, et al. Detection of herpesvirus DNA in the large intestine of patients with ulcerative colitis and Crohn's disease using the nested polymerase chain reaction. Journal of medical virology 1992; 38(3): 183-90.

11. Yanai H, Shimizu N, Nagasaki S, Mitani N, Okita K. Epstein-Barr virus infection of the colon with inflammatory bowel disease. The American journal of gastroenterology 1999; 94(6): 1582-6.

12. Bertalot G, Villanacci V, Gramegna M, et al. Evidence of Epstein-Barr virus infection in ulcerative colitis. Dig Liver Dis 2001; 33(7): 551-8.

13. Nahar S, Iraha A, Hokama A, et al. Evaluation of a multiplex PCR assay for detection of cytomegalovirus in stool samples from patients with ulcerative colitis. World journal of gastroenterology 2015; 21(44): 12667-75.

14. Shimada T, Nagata N, Okahara K, et al. PCR detection of human herpesviruses in colonic mucosa of individuals with inflammatory bowel disease: Comparison with individuals with immunocompetency and HIV infection. PloS one 2017; 12(9): 
e0184699.

15. Froslie KF, Jahnsen J, Moum BA, Vatn MH, Group I. Mucosal healing in inflammatory bowel disease: results from a Norwegian population-based cohort. Gastroenterology 2007; 133(2): 412-22.

16. Schroeder KW, Tremaine WJ, Ilstrup DM. Coated oral 5-aminosalicylic acid therapy for mildly to moderately active ulcerative colitis. A randomized study. The New England journal of medicine 1987; 317(26): 1625-9.

17. Silverberg MS, Satsangi J, Ahmad T, et al. Toward an integrated clinical, molecular and serological classification of inflammatory bowel disease: report of a Working Party of the 2005 Montreal World Congress of Gastroenterology. Canadian journal of gastroenterology = Journal canadien de gastroenterologie 2005; 19 Suppl A: 5A-36A.

18. Tanaka T, Kogawa K, Sasa H, Nonoyama S, Furuya K, Sato K. Rapid and simultaneous detection of 6 types of human herpes virus (herpes simplex virus, varicella-zoster virus, Epstein-Barr virus, cytomegalovirus, human herpes virus 6A/B, and human herpes virus 7) by multiplex PCR assay. Biomedical research 2009; 30(5): 279-85. 
19. Shukla T, Singh S, Tandon P, McCurdy JD. Corticosteroids and Thiopurines,

But Not Tumor Necrosis Factor Antagonists, are Associated With Cytomegalovirus

Reactivation in Inflammatory Bowel Disease: A Systematic Review and Meta-Analysis.

Journal of clinical gastroenterology 2016.

20. Kopylov U, Eliakim-Raz N, Szilagy A, Seidman E, Ben-Horin S, Katz L.

Antiviral therapy in cytomegalovirus-positive ulcerative colitis: a systematic review and meta-analysis. World journal of gastroenterology 2014; 20(10): 2695-703.

21. Shukla T, Singh S, Loftus EV, Jr., Bruining DH, McCurdy JD. Antiviral Therapy in Steroid-refractory Ulcerative Colitis with Cytomegalovirus: Systematic Review and Meta-analysis. Inflammatory bowel diseases 2015; 21(11): 2718-25.

22. Kishore J, Ghoshal U, Ghoshal UC, et al. Infection with cytomegalovirus in patients with inflammatory bowel disease: prevalence, clinical significance and outcome. Journal of medical microbiology 2004; 53(Pt 11): 1155-60.

23. Tanaka N, Cole AJ, von Pechmann D, et al. Dynamic statistical parametric mapping for analyzing ictal magnetoencephalographic spikes in patients with intractable frontal lobe epilepsy. Epilepsy research 2009; 85(2-3): 279-86.

24. Ramanathan J, Rammouni M, Baran J, Jr., Khatib R. Herpes simplex virus 
esophagitis in the immunocompetent host: an overview. The American journal of gastroenterology 2000; 95(9): 2171-6.

25. el-Serag HB, Zwas FR, Cirillo NW, Eisen RN. Fulminant herpes colitis in a patient with Crohn's disease. Journal of clinical gastroenterology 1996; 22(3): 220-3.

26. Schunter MO, Walles T, Fritz P, et al. Herpes simplex virus colitis complicating ulcerative colitis: A case report and brief review on superinfections. Journal of Crohn's \& colitis 2007; 1(1): 41-6.

27. Smith JO, Sterling RK, Mills AS, et al. Herpes simplex virus colitis in a patient with Crohn's disease and hepatitis B and d cirrhosis. Gastroenterology \& hepatology 2010; 6(2): 120-2.

28. Gupta G, Lautenbach E, Lewis JD. Incidence and risk factors for herpes zoster among patients with inflammatory bowel disease. Clinical gastroenterology and hepatology : the official clinical practice journal of the American Gastroenterological Association 2006; 4(12): 1483-90.

29. Pui JC, Furth EE, Minda J, Montone KT. Demonstration of varicella-zoster virus infection in the muscularis propria and myenteric plexi of the colon in an HIV-positive patient with herpes zoster and small bowel pseudo-obstruction (Ogilvie's 
syndrome). The American journal of gastroenterology 2001; 96(5): 1627-30.

30. Chan PK, Li CK, Chik KW, et al. Risk factors and clinical consequences of human herpesvirus 7 infection in paediatric haematopoietic stem cell transplant recipients. Journal of medical virology 2004; 72(4): 668-74.

31. Thompson MP, Kurzrock R. Epstein-Barr virus and cancer. Clinical cancer research : an official journal of the American Association for Cancer Research 2004; 10(3): $803-21$.

32. Knosel T, Schewe C, Petersen N, Dietel M, Petersen I. Prevalence of infectious pathogens in Crohn's disease. Pathology, research and practice 2009; 205(4): 223-30.

33. Sankaran-Walters S, Ransibrahmanakul K, Grishina I, et al. Epstein-Barr virus replication linked to B cell proliferation in inflamed areas of colonic mucosa of patients with inflammatory bowel disease. Journal of clinical virology : the official publication of the Pan American Society for Clinical Virology 2011; 50(1): 31-6.

34. Weinberg I, Neuman T, Margalit M, Ayman F, Wolf DG, Ben-Yehuda A. Epstein-barr virus-related diarrhea or exacerbation of inflammatory bowel disease: diagnostic dilemma. Journal of clinical microbiology 2009; 47(5): 1588-90.

35. Waldman WJ, Williams MV, Jr., Lemeshow S, et al. Epstein-Barr 
virus-encoded dUTPase enhances proinflammatory cytokine production by macrophages in contact with endothelial cells: evidence for depression-induced atherosclerotic risk. Brain, behavior, and immunity 2008; 22(2): 215-23.

36. Takahashi Y, Tange T. Prevalence of cytomegalovirus infection in inflammatory bowel disease patients. Diseases of the colon and rectum 2004; 47(5): $722-6$.

37. Kaufman HS, Kahn AC, Iacobuzio-Donahue C, Talamini MA, Lillemoe KD, Hamilton SR. Cytomegaloviral enterocolitis: clinical associations and outcome. Diseases of the colon and rectum 1999; 42(1): 24-30.

38. Cottone M, Pietrosi G, Martorana G, et al. Prevalence of cytomegalovirus infection in severe refractory ulcerative and Crohn's colitis. The American journal of gastroenterology 2001; 96(3): 773-5.

39. Kambham N, Vij R, Cartwright CA, Longacre T. Cytomegalovirus infection in steroid-refractory ulcerative colitis: a case-control study. The American journal of surgical pathology 2004; 28(3): 365-73.

40. Yoshino T, Nakase H, Ueno S, et al. Usefulness of quantitative real-time PCR assay for early detection of cytomegalovirus infection in patients with ulcerative colitis 
refractory to immunosuppressive therapies. Inflammatory bowel diseases 2007; 13(12): 1516-21.

41. Domenech E, Vega R, Ojanguren I, et al. Cytomegalovirus infection in ulcerative colitis: a prospective, comparative study on prevalence and diagnostic strategy. Inflammatory bowel diseases 2008; 14(10): 1373-9.

42. Lawlor G, Moss AC. Cytomegalovirus in inflammatory bowel disease: pathogen or innocent bystander? Inflammatory bowel diseases 2010; 16(9): 1620-7.

43. Kojima T, Watanabe T, Hata K, Shinozaki M, Yokoyama T, Nagawa H. Cytomegalovirus infection in ulcerative colitis. Scandinavian journal of gastroenterology 2006; 41(6): 706-11.

44. Waldrop SL, Pitcher CJ, Peterson DM, Maino VC, Picker LJ. Determination of antigen-specific memory/effector CD4+ T cell frequencies by flow cytometry: evidence for a novel, antigen-specific homeostatic mechanism in HIV-associated immunodeficiency. The Journal of clinical investigation 1997; 99(7): 1739-50.

45. Nakase H, Chiba T. TNF-alpha is an important pathogenic factor contributing to reactivation of cytomegalovirus in inflamed mucosa of colon in patients with ulcerative colitis: lesson from clinical experience. Inflammatory bowel diseases 2010; 
16(4): $550-1$.

46. Nakase H, Yoshino T, Honzawa Y, Chiba T. Low prevalence of CMV infection in patients with Crohn's disease in comparison with ulcerative colitis: effect of different immune response on prevalence of CMV infection. Digestive diseases and sciences 2010; 55(5): 1498-9.

47. Wada Y, Matsui $\mathrm{T}$, Matake $\mathrm{H}$, et al. Intractable ulcerative colitis caused by cytomegalovirus infection: a prospective study on prevalence, diagnosis, and treatment. Diseases of the colon and rectum 2003; 46(10 Suppl): S59-65.

48. Matsuoka K, Iwao Y, Mori T, et al. Cytomegalovirus is frequently reactivated and disappears without antiviral agents in ulcerative colitis patients. The American journal of gastroenterology 2007; 102(2): 331-7.

49. Forbes BA, Bonville CA, Dock NL. The effects of a promoter of cell differentiation and selected hormones on human cytomegalovirus infection using an in vitro cell system. The Journal of infectious diseases 1990; 162(1): 39-45.

50. Widmann T, Sester U, Gartner BC, et al. Levels of CMV specific CD4 T cells are dynamic and correlate with CMV viremia after allogeneic stem cell transplantation. PloS one 2008; 3(11): e3634. 
51. Adler SP, Hempfling SH, Starr SE, Plotkin SA, Riddell S. Safety and immunogenicity of the Towne strain cytomegalovirus vaccine. The Pediatric infectious disease journal 1998; 17(3): 200-6.

52. Lamoth F, Jayet PY, Aubert JD, et al. Case report: human herpesvirus 6 reactivation associated with colitis in a lung transplant recipient. Journal of medical virology 2008; 80(10): 1804-7.

53. Delbridge MS, Karim MS, Shrestha BM, McKane W. Colitis in a renal transplant patient with human herpesvirus-6 infection. Transplant infectious disease : an official journal of the Transplantation Society 2006; 8(4): 226-8.

54. Mendez JC, Dockrell DH, Espy MJ, et al. Human beta-herpesvirus interactions in solid organ transplant recipients. The Journal of infectious diseases 2001; 183(2): $179-84$.

55. Harma M, Hockerstedt K, Lyytikainen O, Lautenschlager I. HHV-6 and HHV-7 antigenemia related to CMV infection after liver transplantation. Journal of medical virology 2006; 78(6): 800-5.

56. Aalto SM, Linnavuori K, Peltola H, et al. Immunoreactivation of Epstein-Barr virus due to cytomegalovirus primary infection. Journal of medical virology 1998; 
56(3): 186-91. 


\section{Tables}

TABLE 1. IBD Patient Demographic and Disease Characteristics

\begin{tabular}{|c|c|c|c|}
\hline & $\begin{array}{l}\text { Controls } \\
n=29\end{array}$ & $\begin{array}{l}\text { Ulcerative colitis } \\
\qquad n=66\end{array}$ & $\begin{array}{c}\text { Crohn's disease } \\
\qquad n=54\end{array}$ \\
\hline Age, median (interquartile range) & $64.9(58.0-73.0)$ & $48.3(34.5-60.8)$ & $36.9(28.3-42.0)$ \\
\hline Gender (male / female) & $17 / 12$ & $37 / 29$ & $42 / 12$ \\
\hline \multicolumn{4}{|l|}{ Ulcerative colitis } \\
\hline \multicolumn{4}{|l|}{ Extent of disease } \\
\hline Proctitis & & 4 & \\
\hline Left-sided colitis & & 17 & \\
\hline Pancolitis & & 45 & \\
\hline \multicolumn{4}{|l|}{ Crohn's disease } \\
\hline \multicolumn{4}{|l|}{ Disease location } \\
\hline Ileum only & & & 13 \\
\hline Colon only & & & 7 \\
\hline Ileum and colon & & & 34 \\
\hline \multicolumn{4}{|l|}{ Disease behavior } \\
\hline Non-stricturing non-penetrating & & & 13 \\
\hline Stricturing & & & 23 \\
\hline Penetrating & & & 17 \\
\hline \multicolumn{4}{|l|}{ Mucosal inflammation (+ / -) } \\
\hline \multicolumn{4}{|l|}{ MES (Ulcerative colitis) } \\
\hline $0 / 1 / 2 / 3$ & & $30 / 5 / 17 / 14$ & \\
\hline \multicolumn{4}{|l|}{ Medication, n (\%) } \\
\hline Mesalamine & & $54(81.8)$ & $41(75.9)$ \\
\hline Corticosteroids & & $20(30.3)$ & $2(3.7)$ \\
\hline AZA or 6-MP & & $8(12.1)$ & $19(35.2)$ \\
\hline CyA or TAC & & $6(6.8)$ & $0(0.0)$ \\
\hline IFX & & $1(1.5)$ & $20(37.0)$ \\
\hline
\end{tabular}

AZA, azathioprine; 6-MP, 6-mercaptopurine; CyA, cyclosporine A; TAC, tacrolimus; IFX, infliximab; MES, Mayo endoscopic subscore 
TABLE 2. Primers used in the multiplex PCR

\begin{tabular}{|c|c|c|c|}
\hline Virus & Sequence $\left(5^{\prime}-3^{\prime}\right)$ & Position & Amplicon size (bp) \\
\hline \multirow[t]{4}{*}{ HSV $-1 / 2$} & F: GCCAAGAAAAAGTACATCGGCGTCATC & HSV-1: 3389 & 292 \\
\hline & & HSV-2: 3058 & \\
\hline & R: TGAGGACAAAGTCCTGGATGTCCСTCT & HSV-1: 3680 & \\
\hline & & HSV-2: 3349 & \\
\hline \multirow[t]{2}{*}{ VZV } & F: TCCGACATGCAGTCAATTTCAACGTC & 49651 & 161 \\
\hline & R: GGTCGGGTAGACGCTACCACTCGTTT & 49811 & \\
\hline \multirow[t]{2}{*}{ EBV } & F: CTTAGAATGGTGGCCGGGCTGTAAAAT & 153240 & 229 \\
\hline & R: ATCCAGTACGTCTTTGTGGAGCCCAAG & 153468 & \\
\hline \multirow[t]{2}{*}{ CMV } & F: GCGCGTACCGTTGAAAGAAAAGCATAA & 80362 & 131 \\
\hline & R: TGGGCACTCGGGTCTTCATCTCTTTAC & 80492 & \\
\hline \multirow[t]{4}{*}{ HHV-6A/B } & F: ATGCGCCATCATAATGCTCGGATACA & HHV-6A: 57837 & 183 \\
\hline & & HHV-6B: 58791 & \\
\hline & R: CCCTGCATTCTTACGGAAGCAAAACG & HHV-6A: 58019 & \\
\hline & & HHV-6B: 58973 & \\
\hline \multirow[t]{2}{*}{ HHV-7 } & F: GCCCGTTTTCGGAAATATTGGAGAGAT & 55671 & 347 \\
\hline & R: ACGCACGAGACGCACTTTTCTTAAACA & 56017 & \\
\hline
\end{tabular}

HSV, herpes simplex virus; VZV, Varicella-Zoster virus; EBV, Epstein-Barr virus; CMV, cytomegalovirus; HHV, human herpes virus 
TABLE 3. Prevalence of human herpes virus DNA in colonic mucosa

\begin{tabular}{lcccc}
\hline Herpes virus & controls & Ulcerative colitis & Crohn's disease & $P$ value \\
& $\mathrm{n}=29$ & $\mathrm{n}=66$ & $\mathrm{n}=54$ & \\
\hline HSV-1/2 & 0 & 0 & 0 & \\
VZV & 0 & 0 & 0 & \\
EBV & 0 & $14 / 66(21.2 \%)$ & $5 / 54(9.3 \%)$ & $0.001>$ \\
CMV & $1 / 29(3.4 \%)$ & $10 / 66(15.2 \%)$ & 0 & 0.003 \\
HHV-6A/B & $2 / 29(6.9 \%)$ & $6 / 66(9.1 \%)$ & $5 / 54(9.3 \%)$ & 1 \\
HHV-7 & 0 & $1 / 66(1.5 \%)$ & $2 / 54(3.7 \%)$ & 0.594 \\
& & & & \\
\hline
\end{tabular}

HSV, herpes simplex virus; VZV, Varicella-Zoster virus; EBV, Epstein-Barr virus; CMV, cytomegalovirus;

HHV, human herpes virus

TABLE 4. Prevalence of human herpes viruses related to the endoscopic severity of ulcerative colitis

\begin{tabular}{lccccc}
\hline Herpes virus & MES 0 & MES 1 & MES 2 & MES 3 & $P$ value \\
& $\mathrm{n}=30$ & $\mathrm{n}=5$ & $\mathrm{n}=17$ & $\mathrm{n}=14$ & \\
HSV-1/2 & 0 & & & 0 \\
VZV & 0 & 0 & 0 & 0 \\
EBV & $1 / 30(3.3 \%)$ & $2 / 5(40 \%)$ & $8 / 17(47.1 \%)$ & $3 / 14(21.4 \%)$ & 0.001 \\
CMV & $1 / 30(3.3 \%)$ & 0 & $5 / 17(29.4 \%)$ & $4 / 14(28.6 \%)$ & 0.019 \\
HHV-6A/B & $2 / 30(6.7 \%)$ & $1 / 5(20 \%)$ & $2 / 17(11.8 \%)$ & $1 / 14(7.1 \%)$ & 0.662 \\
HHV-7 & $1 / 30(3.3 \%)$ & 0 & 0 & 0 & 1 \\
& & & & & \\
\hline
\end{tabular}

MES, Mayo endoscopic subscore; HSV, herpes simplex virus; VZV, Varicella-Zoster virus; EBV,

Epstein-Barr virus; CMV, cytomegalovirus; HHV, human herpes virus 
TABLE 5. Risk factors for EBV, CMV and HHV-6 infection in patients with ulcerative colitis and Crohn's disease: univariate analysis

\begin{tabular}{|c|c|c|c|c|c|c|}
\hline & \multicolumn{2}{|l|}{ EBV } & \multicolumn{2}{|l|}{ CMV } & \multicolumn{2}{|l|}{ HHV-6 } \\
\hline & Odds ratio $(95 \% \mathrm{Cl})$ & $P$ value & Odds ratio $(95 \% \mathrm{Cl})$ & $P$ value & Odds ratio $(95 \% \mathrm{Cl})$ & $P$ value \\
\hline Age & $0.99(0.96-1.02)$ & 0.372 & $1.03(0.99-1.07)$ & 0.120 & $1.01(0.98-1.05)$ & 0.475 \\
\hline \multicolumn{7}{|l|}{ Gender } \\
\hline Female & Ref & - & Ref & - & Ref & - \\
\hline Male & $1.27(0.452-3.56)$ & 0.651 & $0.99(0.28-3.56)$ & 0.993 & $1.31(0.38-4.47)$ & 0.668 \\
\hline \multicolumn{7}{|l|}{ Disease } \\
\hline Control & Ref & - & Ref & - & Ref & - \\
\hline Ulcerative colitis & $3.11 \mathrm{E}+07(0-\operatorname{lnf})$ & 0.989 & $5.00(0.61-41)$ & 0.134 & $1.35(0.26-7.13)$ & 0.724 \\
\hline Crohn's disease & $1.18 E+07(0-\operatorname{lnf})$ & 0.989 & 8.91E-08 (0-Inf) & 0.991 & $1.38(0.26-7.13)$ & 0.713 \\
\hline \multicolumn{7}{|c|}{ Mucosal inflammation } \\
\hline Noninflamed & Ref & - & Ref & - & Ref & - \\
\hline Inflamed & $10.20(3.16-32.80)$ & $0.001>$ & $10.60(2.20-51.40)$ & 0.003 & $1.26(0.39-4.08)$ & 0.696 \\
\hline \multicolumn{7}{|l|}{ Medication } \\
\hline \multicolumn{7}{|l|}{ 5-ASA } \\
\hline No & Ref & - & Ref & - & Ref & - \\
\hline Yes & $2.69(0.96-7.51)$ & 0.059 & $1.35(0.39-4.62)$ & 0.635 & $0.66(0.21-2.13)$ & 0.490 \\
\hline \multicolumn{7}{|l|}{ Corticosteroids } \\
\hline No & Ref & - & Ref & - & Ref & - \\
\hline Yes & 3.29 (1.09-9.88) & 0.034 & $14.30(3.76-54.80)$ & $0.001>$ & $0.46(0.06-3.70)$ & 0.462 \\
\hline \multicolumn{7}{|l|}{ AZA or 6-MP } \\
\hline No & Ref & - & Ref & - & Ref & - \\
\hline Yes & $2.13(0.88-5.16)$ & 0.093 & $0.90(0.21-3.76)$ & 0.881 & $2.14(0.79-5.84)$ & 0.136 \\
\hline \multicolumn{7}{|l|}{ CyA or TAC } \\
\hline No & Ref & - & Ref & - & Ref & - \\
\hline Yes & $4.13(1.700-10.10)$ & 0.002 & $1.63(0.53-5.00)$ & 0.392 & $2.45(0.99-6.04)$ & 0.052 \\
\hline \multicolumn{7}{|l|}{ IFX } \\
\hline No & Ref & - & Ref & - & Ref & - \\
\hline Yes & $1.77(0.53-5.97)$ & 0.356 & $0.59(0.07-4.86)$ & 0.624 & $0.48(0.06-3.92)$ & 0.496 \\
\hline
\end{tabular}

$\mathrm{Cl}$, confidence interval; EBV, Epstein-Barr virus; CMV, cytomegalovirus; HHV, human herpes virus; 5-ASA,

5-aminosalicylic acid; AZA, azathioprine; 6-MP, 6-mercaptopurine; CyA, cyclosporine A; TAC, tacrolimus; IFX, infliximab 
TABLE 6. Risk factors for EBV, CMV and HHV-6 infection in patients with ulcerative colitis and Crohn's disease: multivariate analysis

\begin{tabular}{|c|c|c|c|c|c|c|}
\hline & \multicolumn{2}{|l|}{ EBV } & \multicolumn{2}{|l|}{ CMV } & \multicolumn{2}{|l|}{ HHV-6 } \\
\hline & Odds ratio $(95 \% \mathrm{Cl})$ & $P$ value & Odds ratio $(95 \% \mathrm{Cl})$ & $P$ value & Odds ratio $(95 \% \mathrm{Cl})$ & $P$ value \\
\hline Age & & & $1.06(0.99-1.11)$ & 0.054 & & \\
\hline \multicolumn{7}{|l|}{ Disease } \\
\hline Control & & & Ref & - & & \\
\hline Ulcerative colitis & & & $1.54(0.09-27.80)$ & 0.770 & & \\
\hline Crohn's disease & & & 5.81E-08 (0-Inf) & 0.994 & & \\
\hline \multicolumn{7}{|l|}{ Mucosal } \\
\hline \multicolumn{7}{|l|}{ inflammation } \\
\hline Noninflamed & Ref & - & Ref & - & & \\
\hline Inflamed & $7.56(2.08-27.40)$ & 0.002 & $6.74(0.59-77.60)$ & 0.126 & & \\
\hline \multicolumn{7}{|l|}{ Medication } \\
\hline \multicolumn{7}{|l|}{ 5-ASA } \\
\hline No & Ref & - & & & & \\
\hline Yes & $2.05(0.65-6.52)$ & 0.223 & & & & \\
\hline \multicolumn{7}{|l|}{ Corticosteroids } \\
\hline No & Ref & - & Ref & - & & \\
\hline Yes & $0.83(0.21-3.31)$ & 0.796 & $5.24(0.91-30.30)$ & 0.064 & & \\
\hline \multicolumn{7}{|l|}{ AZA or 6-MP } \\
\hline No & Ref & - & & & Ref & - \\
\hline Yes & $1.53(0.56-4.18)$ & 0.408 & & & $1.86(0.66-5.26)$ & 0.243 \\
\hline \multicolumn{7}{|l|}{ CyA or TAC } \\
\hline No & Ref & - & & & Ref & - \\
\hline Yes & $2.22(0.84-5.85)$ & 0.106 & & & $2.23(0.87-5.69)$ & 0.094 \\
\hline
\end{tabular}

$\mathrm{Cl}$, confidence interval; EBV, Epstein-Barr virus; CMV, cytomegalovirus; HHV, human herpes virus; 5-ASA,

5-aminosalicylic acid; AZA, azathioprine; 6-MP, 6-mercaptopurine; CyA, cyclosporine A; TAC, tacrolimus; IFX, infliximab 
TABLE 7. A multivariate Cox proportional hazard analysis of risk factor for colectomy in patient with ulcerative colitis.

\begin{tabular}{lcccc}
\hline & Unadjusted HR $(95 \% \mathrm{Cl})$ & $P$ value & Adjusted HR $(95 \% \mathrm{Cl})$ & $P$ value \\
\hline Infection pattern & Ref & - & Ref & - \\
Un-infection & $0.75(0.08-7.20)$ & 0.802 & $1.39(0.08-24.6)$ & 0.824 \\
Single-infection & $8.74(1.44-53.15)$ & 0.019 & $72.3(1.85-2.82 \mathrm{E}+03)$ & 0.022 \\
Combined-infection & & & & \\
\hline
\end{tabular}

Adjusted for partial Mayo score, Mayo endoscopic subscore, serum albumin level, serum C-reactive protein level, and anti-viral therapy

\begin{tabular}{lcccc}
\hline & Unadjusted $\mathrm{HR}(95 \% \mathrm{Cl})$ & $P$ value & Adjusted $\mathrm{HR}(95 \% \mathrm{Cl})$ & $P$ value \\
\hline Anti-viral therapy & Ref & - & Ref & - \\
No & $6.26(0.72-54.0)$ & 0.095 & $0.31(4.13 \mathrm{E}-03-23.2)$ & 0.595 \\
Yes &
\end{tabular}

$\mathrm{HR}$, hazard ratio; $\mathrm{Cl}$, confidence interval

Adjusted for partial Mayo score, Mayo endoscopic subscore, serum albumin level, serum C-reactive protein level, and infection pattern 


\section{Figure Legends}

FIGURE 1. Combined infection of human herpes viruses in inflammatory bowel

disease (IBD)

Venn diagram representing the overlap of Epstein-Barr virus (EBV), cytomegalovirus

(CMV) and human herpes virus type 6 (HHV-6) infections. Inside of the dotted box shows the patients with ulcerative colitis (UC).

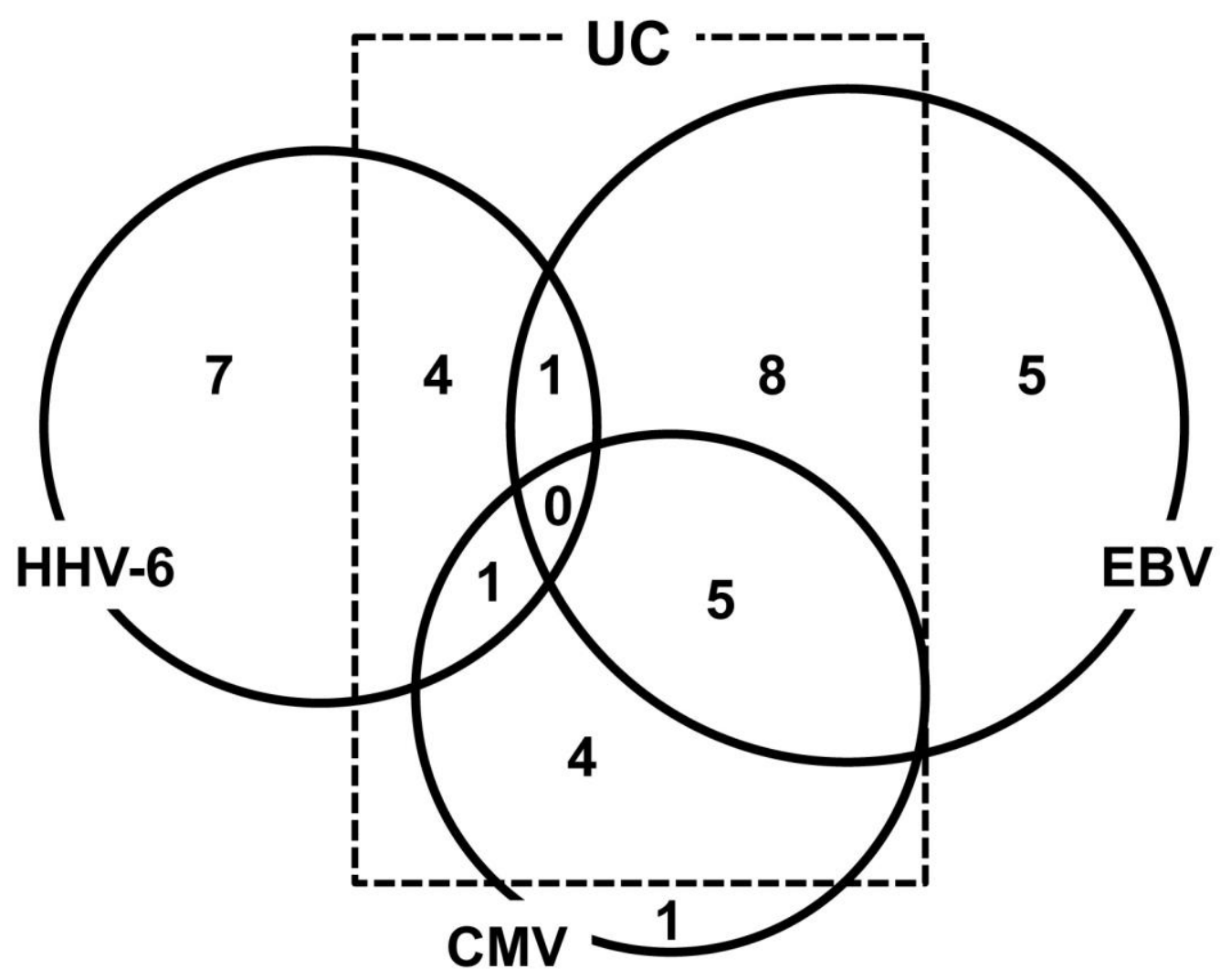

